
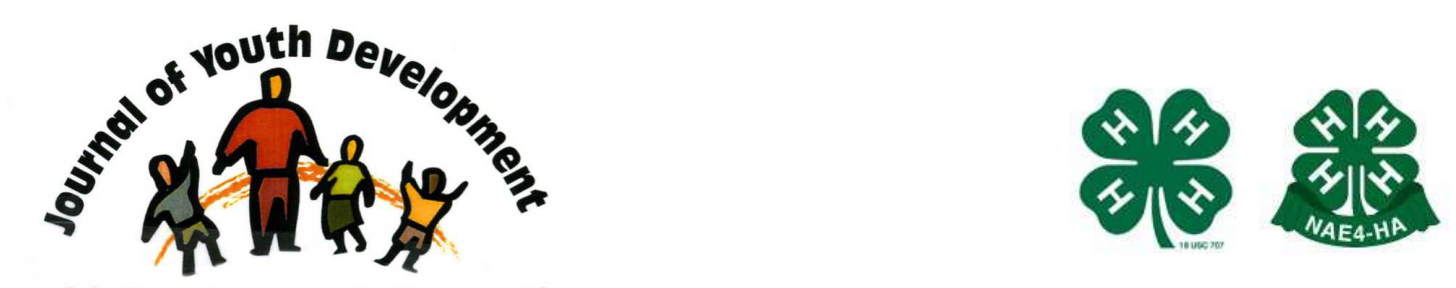

Bridging Research \& Practice

\title{
A Qualitative Examination of Youth Voice in the Decision-Making Process within the 4-H Youth Development Program: Promoting Promising Practices in Overcoming Barriers
}

\author{
Janet Fox \\ 4-H Youth Development \\ Louisiana State University AgCenter \\ Baton Rouge, LA \\ jox@agcenter.Isu.edu \\ Todd Tarifa \\ 4-H Youth Development \\ Louisiana State University AgCenter \\ Baton Rouge, LA \\ tatarifa@agcenter.Isu.edu \\ Krisanna Machtmes \\ School of Human Resource Education and Workforce Development \\ Louisiana State University \\ Baton Rouge, LA \\ machtme@agcenter.Isu.edu
}




\title{
JOURNAL OF YOUTH DEVELOPMENT \\ bridging research and practice
}

\section{A Qualitative Examination of Youth Voice in the Decision-Making Process within the 4-H Youth Development Program: Promoting Promising Practices in Overcoming Barriers}

\author{
Janet Fox, Todd Tarifa and Krisanna Machtmes \\ Louisiana State University
}

\begin{abstract}
This paper discusses a national study designed to identify and describe obstacles to youth voice in the decision-making process in the $4-\mathrm{H}$ youth development program from the perception of three distinct populations - State 4-H Program Leaders, 4-H State Youth Development Specialists, and 4-H Youth Agents/Educators. When examining these professionals' views on the barriers affecting youth voice in the decision-making process, time and scheduling seem to consistently present the largest barrier to youth voice. Involvement in the decision-making process provides a wide range of hurdles including the opportunity structures, involvement procedures, representation and dynamics within the process. Adult power and control provides a significant hurdle to authentic engagement of youth voice in the decision-making progress. Respect barriers were described by concepts such as preconceived notions, trust and valuing input. Additional barriers were identified including organizational culture, lack of transportation, lack of knowledge/experience, lack of preparation, lack of training, fear, misguided leadership, unclear expectations, participation, staffing and lack of resources.
\end{abstract}

\section{Introduction}

Youth development is the process of positively developing a young person's capacities by promoting the psychological, emotional, physical and spiritual growth of youth to help them transition into adulthood. Within organizations, positive youth development takes place intentionally as a course of action that encourages and supports positive results for youth. Through the process of youth development, young people become focused on achievement and 
goals, work in the direction of those goals, and avoid behaviors that would prevent the attainment of those goals (Hirschi, 1969).

\section{Relevant Literature}

Youth development organizations such as 4-H prepare young people to meet the challenges of adolescence positively transitioning into adulthood through a well conceived, progressive sequence of activities and experiences that promote social, emotional, ethical, physical, and cognitive competencies. They address the broader developmental assets all youth need, such as: caring relationships, safe places and activities, both physical and mental health, life skills, and opportunities for community service and civic participation (National Youth Development Information Center, 2000).

Youth development programs engage youth in activities, programs and environments that will enable them to gain critical life skills while meeting their basic human needs. Research on youth development programs has identified the following key elements:

- a comprehensive strategy with clear mission and goals;

- committed, caring professional leadership; youth-centered activities in youth-accessible facilities;

- culturally competent and diverse programs;

- youth ownership and involvement, and

- a positive focus including all youth (National Youth Development Information Center, 2000).

Exceptional youth development programs empower youth to make informed decisions, engage in actions based on their informed decision, and feel that they have the ability to make choices that affect their lives (Pittman, \& Wright, 1991).

One of the key elements of youth development programs is youth ownership and involvement. Youth voice is the involvement of youth in policy, program creation, development, implementation, and evaluation. A youth development program should recognize positive youth participation practices of nurturing, valuing and respecting young people and their ability to meaningfully contribute to issues and decisions that affect their lives (Ministry of Youth Affairs, 2002). Youth development programs must aid young people in developing their sense of voice in order to prepare them to be successful in today's fast changing world (Larson, 2000).

Inclusion of youth voice entails taking risks and working together with youth to accomplish the mission of the organization (Fletcher, 2002). However, youth development programs that build relationships and effectively engage youth in the decision-making process provide well planned and structured programs that promote positive youth development (Redd, Brooks, \& McGarvey, 2002).

In the field of youth development, adults frequently organize and implement projects with little or no involvement by youth in the decision-making process (Kothari, 1996). For many youth serving organizations, inclusion of youth voice would require a change in the culture and a shift in the paradigm of adults controlling the programming within 4-H (Hillison, 1996). However, the shift is well worth it. Research has shown that conventional planning led by adults is failing our young people (Frank, 2006; Meucci, \& Redmon, 1997). Newsome and Scarela (2001) found 
that organizations planning their programs based on the desires and preferences of adults make youth feel disconnected, alienated, unsupported, and unacknowledged by adults.

With the many opportunities that youth development organizations provide youth today, it is vital that these organizations allow them to become a larger contributor to the decision-making process to aid in recruiting and retaining young people. The fact is that youth are affected by an organization; therefore, these organizations should give youth the right to voice their opinions and ideas on how the organization is run. Youth understand the needs and desires of their peers and the manner in which they can be reached (Kothari, 1996; Laidlaw Foundation, 2001).

In addition to benefiting the organization, inclusion of youth voice has many advantages for youth as they gain valuable skills. Some of these include social and leadership skills from being included in the decision-making process (Kothari, 1996; Laidlaw Foundation, 2001; Pittman, \& Wright, 1991). Allowing youth to have a voice in the decision-making process means that a youth-serving organization needs to take youth's ideas and opinions into consideration and respect what they have to say. Engaging and empowering youth teaches them to define and communicate their concerns and interests thus, helping them design, discuss and implement programs that meet their interest and concerns (Pittman, \& Wright, 1991). Youth benefit from the learning process of being involved and planning programs, and they develop a sense of ownership and consecutiveness with the organization (Kothari, 1996). By allowing youth to have a voice, youth organizations tap into the unique perspective and ability of youth and the creativity and energy they bring with them to the table. Overall, youth organizations are equipping youth with the tools they need to become more active members of their community (Frank, 2006; Laidlaw Foundation, 2001; Pittman, 2000).

Procedures for engagement, suggested settings, length of activities, age-appropriate activities and barriers to youth voice are all issues that will challenge youth development educators (Checkoway, Figueroa, \& Richards-Schuster, 2003; Justinianno, \& Scherer, 2001; Mason, \& Goll, 2000; Scales, \& Leffert, 1999; Young, \& Sazama, 1999; Zeldin, McDaniel, Topitzes, \& Calvert, 2000). Youth organizations often reinvent the wheel because of the lack of studies that identify how youth-serving organizations can promote youth voice and break down barriers that prevent youth voice in the decision-making process. There is a strong need for studies that identify if we are truly including youth in the decision-making process (Frank, 2006; Knowles-Yánez, 2005).

\section{Purpose and Objectives}

Within the framework of this research, youth voice is the concept that will be examined to shed light on the barriers of the engagement of young people. The purpose of this study is to identify the barriers that limit youth participation and recommendations based on these barriers that encourage youth voice.

\section{Methodology}

Population and Sample. National in scope, the study consisted of three significant professional groups within the 4-H youth development program: (1) the State 4-H Program Leaders in all 50 states, (2) the State 4-H Youth Development Specialists in all 50 states, and 
(3) five 4-H Youth Agents/Educators in Cooperative Extension county/parish offices in each state. The first population, 4-H Program Leaders in all 50 states, and the second population, 4-H Youth Development Specialists in each state were identified through the USDA Cooperative State Research, Education, and Extension Service website directory. All 50 State 4-H Offices were contacted to verify 4-H Youth Development Specialists. Identified by the State 4-H Program Leaders, the third population, 4-H Youth Agents/Educators, were selected based on the diversity and demographics of their state to complete the survey. Prior to the survey, a letter was sent via e-mail to each state's 4-H Program Leader, 4-H Youth Development Specialists, and 4-H Youth Agents/Educators to notify them of the study.

Instrumentation. An extensive literature review determined that there was not an existing instrument which measured the 4-H program's views on youth voice in the decision-making process. After a thorough review of literature, instruments were developed. Dillman's (2000) electronic survey design and methodology was followed in the study. Approval for implementation of the study was obtained from the Louisiana State University Institutional Review Board for Human Subject Protection prior to the initiation of the survey (3332).

Presupposition questions were developed to obtain data on the participant's perception on barriers to youth voice in the decision-making process. These questions were:

- What is the biggest obstacle to youth voice in the decision-making process within 4-H;

- Why is it the biggest obstacle;

- List any additional concerns or comments you may have regarding the topic of youth voice in the decision-making process.

Data Collection. The researchers administered the instrument via Zoomerang $\subset$ (electronic survey software), to each State's 4-H Program Leader, State 4-H Youth Development Specialists, and five 4-H Youth Agents/Educators in all 50 states at the county/parish level that were selected by the State 4-H Program Leaders to complete the survey.

All participants were sent a cover letter electronically requesting their participation and instructions for completing the survey along with a URL link to the survey. Dillman's (2000) electronic survey design and methodology was followed throughout data collection. A total of 706 participants were asked to complete the survey during the time period extending from May 17,2006 through July 27, 2006. The response rate for each population was $64 \%$ for State $4-\mathrm{H}$ Program Leaders, $46 \%$ for $4-\mathrm{H}$ Youth Development Specialists, and $52 \%$ for $4-\mathrm{H}$ Agents/Educators.

Data Analysis. The qualitative analysis involved examining the assembled relevant data to determine how participants answered the research questions. The data analyses were conducted within the framework of the youth program development. To provide a framework for analyzing the information gleamed, the team of analysts repeatedly asked the following questions:

1. What patterns and common themes emerge in responses dealing with barriers that prevent youth voice? How do these patterns (or lack thereof) help to illuminate the broader context of the situation(s)? 
2. Are there any deviations from these patterns within the populations studied? If yes, are there any factors that might explain these atypical responses?

3. Do the patterns that emerge corroborate the findings of any other corresponding research studies that have been conducted? If not, what might explain these discrepancies?

According to Miles and Huberman (1994), there are three elements of qualitative data analysis: data reduction, data display and drawing conclusions. The mass of data was organized and meaningfully reduced involving deductive and inductive analysis. While shaped by preestablished questions and a literature review, researchers were open to inducing new meanings from the data available and took note of the frequency with which different issues were raised as well as the intensity with which they are expressed. In doing so, the researchers were careful not to "flatten" the data.

Using data display, the researchers arranged the responses in an organized, condensed display of information using a chart for thinking about the more textually embedded data. This data display allowed the team of researchers to extrapolate from the data to discern systematic patterns and interrelationships.

The researchers drew summaries by reflecting upon the analyzed data and what the implications meant. Online survey data and a review of literature were used to cross-check the themes identified from the survey. When drawing conclusions, verification entailed revisiting the data consistently to cross-check the emergent conclusions.

Limitations. The study only focuses on youth voice in the decision-making process as it pertains to 4-H; therefore, the results cannot be generalized to other youth organizations. This study was limited to include only State 4-H Program Leaders, State 4-H Specialists, and 4- $\mathrm{H}$ Agents/Educators who are part of the 4-H program.

\section{Findings}

Demographics. The majority of State 4-H Program Leaders (59\%) and State 4-H Youth Development Specialists (57\%) were male. The overwhelming majority of 4-H Agents/Educators who participated in the study indicated they were female (79\%).

The majority of study population reported their race as "White" with State 4-H Program Leaders at $91 \%, 4-\mathrm{H}$ Youth Development Specialists at $94 \%$ and $4-\mathrm{H}$ Agents at $89 \%$. Table 1 illustrates data regarding the sample's ethnicity. 
Table 1

Ethnicity

\begin{tabular}{|c|c|c|c|c|c|c|}
\hline Ethnicity & $\begin{array}{c}\text { African } \\
\text { American }\end{array}$ & $\begin{array}{c}\text { Asian- } \\
\text { Pacific } \\
\text { Islander }\end{array}$ & Latino & $\begin{array}{c}\text { Native } \\
\text { American }\end{array}$ & White & Other \\
\hline $\begin{array}{c}\text { State 4-H Program } \\
\text { Leader }\end{array}$ & $3.1 \%$ & $0.0 \%$ & $0.0 \%$ & $3.1 \%$ & $90.6 \%$ & $3.1 \%$ \\
\hline $\begin{array}{c}4-\mathrm{H} \text { Youth } \\
\text { Development } \\
\text { Specialist }\end{array}$ & $3.7 \%$ & $0.0 \%$ & $3.7 \%$ & $0.0 \%$ & $93.6 \%$ & $3.7 \%$ \\
\hline $\begin{array}{c}4-\mathrm{H} \\
\text { Agents/Educators }\end{array}$ & $3.1 \%$ & $3.1 \%$ & $1.5 \%$ & $1.5 \%$ & $89.2 \%$ & $1.5 \%$ \\
\hline
\end{tabular}

When it came to highest level of education, the majority of State 4-H Program Leaders (65.6\%) earned a Doctor of Philosophy degree. The largest group of State 4-H Youth Development Specialist (57.2\%) and 4-H Agents/Educators (60\%) reported that they had earned a Masters Degree. Table 2 illustrates data regarding the sample's highest level of education.

Table 2

Highest Level of Education

\begin{tabular}{|l|l|l|l|}
\hline Level of Education & Program Leaders & $\begin{array}{l}\text { Youth Development } \\
\text { Specialist }\end{array}$ & 4-H Agent \\
\hline BS/BA & 0.0 & 9.6 & 36.9 \\
\hline MA/MS/Med & 31.3 & 57.2 & 60.0 \\
\hline PhD/EdD & 65.6 & 33.2 & 2.3 \\
\hline MD/DVM/JD/DD & 3.1 & 0 & 0.8 \\
\hline Total & 100.0 & 100.0 & 100.0 \\
\hline
\end{tabular}

Youth Voice Barriers. The major objective of the study was to gather information, utilizing open-ended questions, from State 4-H Program Leaders, 4-H Youth Specialist, and 4-H Agents/Educators on the obstacles that they perceived affected youth voice in the decisionmaking process within the 4-H youth development program. When asked the question "What is the biggest obstacle to youth voice in the decision-making process within 4-H?," all three populations responded that involvement, lack of experience/knowledge, organizational culture, power/control, respect/value of youth voice, time/scheduling, and transportation were barriers of youth voice in the decision-making process within the 4-H program. Table 3 illustrates the emerging themes for the question, "What is the biggest obstacle to youth voice in the decisionmaking process within $4-\mathrm{H}$ ?" 
Table 3

Biggest Obstacle to Youth Voice in the Decision-making Process within 4-H

\begin{tabular}{|c|c|c|c|}
\hline Theme & $\begin{array}{l}\text { State 4-H } \\
\text { Program } \\
\text { Leaders }^{\mathrm{a}}\end{array}$ & $\begin{array}{l}\text { 4-H Youth } \\
\text { Development } \\
\text { Specialists }^{b}\end{array}$ & $\begin{array}{c}4-\mathrm{H} \\
\text { Agents/Educators }\end{array}$ \\
\hline Communication & & $x$ & $x$ \\
\hline Diversity & & & $x$ \\
\hline Expectations & & $x$ & $x$ \\
\hline Fear & & $x$ & $x$ \\
\hline Involvement & $x$ & $x$ & $x$ \\
\hline Lack of Experience/Knowledge & $\mathrm{X}$ & $\mathrm{X}$ & $\mathrm{x}$ \\
\hline Leadership & & $x$ & $x$ \\
\hline Organizational Culture & $x$ & $x$ & $x$ \\
\hline Participation & & $x$ & $x$ \\
\hline Policy/Risk Management & $x$ & $\mathrm{X}$ & \\
\hline Power/Control & $x$ & $\mathrm{X}$ & $\mathrm{X}$ \\
\hline Resources & & $x$ & $x$ \\
\hline Respect/Trust & $x$ & $x$ & $x$ \\
\hline Staffing & & & $x$ \\
\hline Time/Schedule & $x$ & $\mathrm{X}$ & $x$ \\
\hline Training & & $x$ & $x$ \\
\hline Transportation & $x$ & $x$ & $\mathrm{x}$ \\
\hline Youth Development & & $x$ & \\
\hline
\end{tabular}

Note. An "X" indicates that the theme emerged within the identified population

${ }^{\mathrm{a}} \mathrm{A}$ total of 32 State 4-H Program Leaders that responded to this particular question.

${ }^{\mathrm{b}} \mathrm{A}$ total of $168 \mathrm{4}-\mathrm{H}$ Youth Development Specialists that responded to this particular question.

${ }^{\mathrm{C}} \mathrm{A}$ total of $114 \mathrm{4}-\mathrm{H}$ Agents/Educators that responded to this particular question.

\section{Time and Scheduling:}

Time and scheduling garnered the most statements from all the groups. Accessibility, availability, scheduling conflicts, competition with other organizations, over commitment, time management, and parents' schedules were all dynamics reported as factors impacting time as an obstacle to youth voice in the decision-making process. A number of comments were made about the difficulty finding a time that accommodates for both youth and adults' schedules can be difficult. 
Accommodating the schedules of youth was a theme within time and scheduling that garnered a wealth of comments including:

"Changing the culture to allow youth to participate by adjusting meeting times and schedules to accommodate them."

"Schedules for both youth and adults work against each other."

"Trying to accommodate schedules of youth and adults, with varying demands, both night and day in order to have meaningful engagement."

Youth being overscheduled was another reoccurring concept related to time as illustrated by the following statements:

"There just aren't enough hours in their schedule for additional responsibilities."

"Youth are already over committed and seem hesitant to get involved."

"Youth are too involved in other activities and other organizations, and it is difficult for them to find time to plan and carry out projects."

"Effort required making it happen."

\section{Involvement:}

Involvement was mentioned the second most frequent with 4- $\mathrm{H}$ Specialists mentioning it the second most number of times and 4-H Agents ranked it fifth with their frequency of comments. Involvement in the decision-making process ranged from the design of the opportunities to involvement procedures to the concept of representation to dynamics within the process.

The design of the involvement opportunities was a complex issue ranging from designing the involvement opportunities to providing a high quality involvement experience to time for and timing of the involvement. The following statements illustrated issues of involvement:

"Ability to convene opportunities for youth to be heard and involved in the program development and implementation."

"Providing youth with information that their voices are important. Then allowing the youth to speak out."

"Lack of an effective structure or process for decision making, particularly at the state level."

"We tend to involve them AFTER adults have come up with the issue/program, etc instead of asking them to help in brainstorming and coming up with the issue/program."

In providing involvement opportunities, the concept of representation came out in comments related to a balance between the number of youth and adults and using the same youth. The following comments illustrate these points:

"Thinking that one youth rep is enough presence to assure their voice is heard."

"The same youth are repeatedly called on to serve, thus excluding many capable youth."

"Identifying youth to be involved that will speak their mind and thoughts, not their parent's views." 
"Adults understanding why youth representation is not only important but necessary for the continuation of the 4-H program."

An additional involvement issue was youth and adult relationship dynamics which was described through the following statements:

"Adults who lack a positive understanding of the contributions youth can make while still participants in the program."

"Many times youth do not realize the power and knowledge they bring to the entire process."

"Adults and youth perceiving equality at the same table."

"...Youth for the most part are told this is what will happen and then go along with the decisions and are given smaller roles in the activity."

\section{Power and Control:}

Power and control was the third most frequent theme identified. Power and control was the theme mentioned second most frequently by $4-\mathrm{H}$ agents and third by $4-\mathrm{H}$ Specialists. Power and control obstacles ranged from adult control issues to negative perspectives of youth capability to adult being over invested in the program to a lack of openness to the inability to share power. Some of the comments regarding power and control within the decision-making process were:

"Adult's fear of youth taking control and adults not getting their way."

"The lack of adults willing to let them have a voice. Then when they do have a voice, the adults allow the youth to believe they will do what they want when they actually have no intention of doing what the youth planned."

"Adult's ability to be quiet and let youth dominate."

"Adults allowing youth to build a responsible partnership in the decision making process."

"Involving adults that will allow youth to make decisions. Failure is part of the process. It's not what failed it's what can we learn from this and do differently so the next time we have different results."

\section{Respect:}

Overall, respect was the fourth most frequently identified theme. Respect or lack thereof, was the second most frequently mentioned theme for State 4-H Program Leaders, the third most frequently mentioned theme for 4-H Agents and the fourth most frequently identified theme for 4-H Youth Development Specialists. Respect was described by concepts such as preconceived notions, trust and valuing input. Preconceived notions were identified as barriers related to respect as illustrated through the following comments:

"Youth and adults having preconceived ideas about each others' capacity."

"Changing the mindset of some adults to value the ideas and skills youth can bring to the planning and implementation process."

"Our inadvertent patronization of youth." 
"Getting adults to open up and to realize that the youth are responsible enough and capable of participating in the decision making processes."

Within the concept of respect was the importance of valuing each other as expressed in the following statements:

"The ability of each to accept and value what the other may bring to the table."

"Adults truly valuing young people as resources and not objects."

"The adults need to honor the youth in the youth-adult partnerships. To see the role of the youth's voice as equal."

"Adults' perception that youth voice is valuable to the 4-H process."

An area within respect, trust was described through the following statements:

"Trust and communication play a major role in youth voice."

"Once the group establishes trust and objectives both groups work better together as a unified team."

"Trust among the youth and adults to be equal players, time to develop this trust and create true partnerships...to bring youth truly into partnerships with us."

Quotes outlining valuing input included:

"Being asked to serve on committees and then the committee members not listening to what they have to say."

"The biggest obstacle is having an equal partnership between youth \& adults when making decisions in 4-H."

"Youth and adults mutually respecting each others opinions and ideas."

"Adults who value and support opinions and input of youth."

"Having adults value their input and to seek their input."

Identified by all three groups, organizational culture was described through the statements regarding tradition and expectations as follows:

"The culture of control by the 4-H faculty member at either the state or county level."

"Changing the culture to allow youth to participate by adjusting meeting times and schedules to accommodate them."

"Inoculating both a culture that expects youth involvement and lack of understanding and knowledge of Youth Development principles and pressures of getting programming done at the service level."

"Culture believes that youth don't have the skills and abilities to live up to the expectations of adults."

"A history of not including them on advisory councils, fair boards, committees, etc. currently doing more of that, but youth and adults aren't used to it and often don't understand/appreciate roles of each." 
"Developing an atmosphere of openness between youth and adults."

Training:

Lack of training was identified by 4-H Youth Development Specialists and 4-H Agents as a barrier to youth voice in the decision-making process. While both groups identified the need to provide training for both youth and adults, 4-H Specialists' comments focused mostly on training adults as illustrated in the following statements:

"Teaching adults how to accept, encourage, and facilitate opportunities for youth voice."

"Providing sufficient training to adults so that they understand the value of youth voice in the decision making process."

"Volunteer adults need to be trained as to how to encourage youth voice by more selfawareness and participatory group process, diversity and respectful communication skills training."

Another aspect of training was identified by 4-H Youth Development Specialists as they discussed the youth voice aligned with their age and ability as demonstrated by the following statements:

"Lack of life experiences sometimes leaves them (youth) without enough information to make good choices or suggestions" and

"neither adolescents nor younger children are developmentally ready or able to effectively take on actual adult decision-making roles and responsibilities for the overall 4-H program, and adults who attempt to engage youth as 'equal partners' in 4-H decisionmaking at all levels are often misguided in what they do."

\section{Transportation:}

Identified by all populations as a challenge, the barrier category of transportation involved the youths' ability to drive, the distance involved in transporting youth as well as the resources to drive or be driven. Statements regarding transportation included:

"Transportation, distance to travel to gather for meetings."

"Travel restrictions for face-to-face meetings of State 4-H officers."

"Distance required to bring all parties together."

"They can't drive or do not have their own car, money is being saved for college and or a car, and they have little time as starting to work and school work and activities are very important."

\section{Experience:}

Noted by all three populations, lack of experience and knowledge dealt with comments regarding both adults and youth. The comments included:

"Youth interest and knowledge level with respect to decisions they might have to make."

"Their lack of life experiences sometimes leaves them without enough information to make good choices or suggestions."

"Experience on the part of both adults and youth." 
"Lack of skills by the adults to encourage youth voice and involvement."

"The lack of opportunity to develop their communication skills in other areas of their lives."

Fear:

Both 4-H Youth Development Specialists and 4-H Agents/Educators identified fear as an obstacle to youth voice in decision-making roles. Interestingly, Specialists recognized adults' fear of letting people down, not being able to make a mistake and fear of allowing youth to take the lead. Conversely, 4-H Agents related fear to youth being made fun of by peers or adults and fear to speak up when adults are around.

Communication issues were addressed between youth and adults, such as communication skills and lack of effective communication tools. Expressed by both 4-H Youth Development Specialists and 4-H Agents/Educators, having clear expectations was outlined through perceptions of each other's expectations, communicating expectations, low expectations, and making a commitment.

A wide variety of other themes emerged including leadership, participation, policy/risk management, and resources. The concept of leadership was identified, which ranged from adult leadership that doesn't value youth voice, to lack of positive 4-H leadership roles for youth. Participation issues addressed active participation, lack of participation, prior negative youth voice experiences, turnover and a lack of success stories. Policy issues were connected to university policy or liability/risk management considerations. Resources involved fiscal and material resources needed to support youth voice such as transportation, time, and computers. Staffing obstacles, shared exclusively by 4-H Agents, related to staff shortages and having capable volunteers to expand staff efforts.

\section{Conclusions and Recommendations}

Conclusions. When examining 4-H youth development professionals' perceptions on the obstacles that affect youth voice in the decision-making process, time and scheduling was consistently present as the largest barrier to youth voice. Time, as a barrier, was a complex concept. The first concept of time related to the time it took as part of a process involved in developing and utilizing youth voice within the decision-making process. The second concept related to issues of busy schedules, the timing of meetings, differing schedules of youth and adults, and conflicting events, activities and priorities. While involvement was mentioned as an aspect of time, it emerged as a separate youth voice barrier. Involvement in the decisionmaking process provides a wide range of characteristics including the opportunity structures for engagement, involvement procedures, adequate representation of youth on boards, and dynamics within the process.

Adult power and control provides a significant barrier to authentic engagement of youth voice in the decision-making process. Power was focused on adult's superiority over youth, adults not having confidence in youths' decision making capabilities, and protecting youth from failing in front of their peers and adults.

Other consistent threads through which most control issues identified were respect and trust. Barriers outlined within the respect construct were described by preconceived notions, trust and 
valuing input. Interestingly, respect often involved including youth representation and not valuing or trusting that they could contribute to the decision-making process. Some of the context of this construct included believing youth don't have the life experiences necessary to be a successful contributor or that they lack the responsibility to follow-up on critical steps.

Organizational culture indicated that the organization did not value youth inclusion throughout multiple levels. While personal views regarding youth voice indicated that youth development professionals realized youth voice should be part of the decision-making process, it was clear that they felt that the organization limited youth voice through policies, history, tradition and conflicting values. Additional barriers included transportation challenges, lack of knowledge/experience, deficiencies in preparation and training, fear, misguided leadership, unclear expectations, participation levels, staffing issues, lack of resources, and developmental fundamentals.

Recommendations. Time and scheduling, money issues, and transportation will always present challenges to participation in today's society. To address these logistical issues, youth development professionals can utilize technology such as conference calls or web chats to support different meeting formats and strategies to engage youth voice. Meeting times can be dovetailed to maximize participation. In addition, instead of meeting as a whole group, once started, smaller groups or committees can meet together to address specific tasks or goals. It's important to make the most of meetings by helping participants come prepared to aid in running the meeting efficiently. The meetings can be "brought" to the youth at their location so transportation isn't an issue. Transportation support can be provided by carpooling and having meetings when parents and other adults can provide travel support.

When finances or resources are a concern, providing scholarships, obtaining grants or having a computer loan system to reduce the financial burden on participants can provide much needed support (Hoover, \& Weisenbrach, 1999; Newsome, \& Scalera, 2001; Parker, 1999).

Research has shown that one of the most critical components to the success of youth voice is the youth-adult partnership. Youth development professionals should view youth as equal partners when it comes to making decisions. It's the responsibility of the youth development professional to address adults who want to control the program and do not allow youth voice in the decision-making process. Professionals can provide training and preparation, model the behavior they wish others to adopt, and address control issues through consultation and guidance (Checkoway, et al., 2003).

Most of the obstacles to youth voice can be remedied through preparation and high quality, experiential training on youth voice. Relevant trainings help youth and adults get on the same page in understanding why youth voice is important and appreciating what each group brings to the table. Preparation for youth voice through such avenues as orientation, position descriptions, team building activities and careful selection of both youth and adults teammates assures that youth and adults become partners and develop meaningful relationships that provide the respect and trust needed for youth voice to thrive.

To build positive relationships, it is critical that youth and adults engage in open, honest dialogues around the strengths and weaknesses each brings to the project. Respectful sharing can create an atmosphere that can result in trust, an essential element to positive youth and 
adult partnerships. Communicating high standards and clear expectations to all that are involved are critical to fostering a positive environment for youth voice (Carstarphen, 2001; Checkoway, et al., 2003; Justinianno, \& Scherer, 2001; Mason, \& Goll, 2000; Young, \& Sazama, 1999; Zeldin, et al., 2000).

While organizational culture can be a difficult area to enhance, it's a vital element in creating a culture of youth voice. The organization needs to be modeled from all levels starting at top to provide an avenue to promote and support youth voice on the front-line. As administration supports youth voice, linking the organizational vision to the role that youth voice plays in its implementation of the programming and support mechanisms is vital. Clear communication and expectations of inclusion of youth voice needs to be demonstrated on multi-levels within the organization. When it comes to promoting and supporting youth voice, experimentation and acceptance of failure must become part of the organizational culture. Professionals must understand that failure is a part of the natural youth development process. To create system's change, involvement of everyone is vital.

Youth development professionals have an obligation to prepare, teach, coach and support both youth and adults in the decision-making process. Youth development professionals have the responsibility to employ facilitation strategies that help promote equal voice. The recommendations from this study should be implemented to insure equal and adequate representation of youth and adults within youth organizations.

\section{References}

Carstarphen, D. (2001). The role of young people in the leadership organization. Washington, DC: Academy for Educational Development.

Checkoway, B., Figueroa, K., \& Richards-Schuster, K. (2003). Democracy multiplied in an urban neighborhood: Youth force in the South Bronx. Children, Youth and Environments, 13, 15462250.

Dillman, D. (2000). Mail and internet surveys, 2nd Ed. New York, NY: John Wiley \& Sons.

Fletcher, A. (2002). Broadening the bounds of involvement: Transforming schools with student voice. Retrieved March 6, 2005 from: www.studentinvolvement.net

Frank, K. (2006). The potential of youth participation in planning. Journal of Planning Literature, 20(4), 351-371.

Hillison, J. (1996). Agricultural Education and Cooperative Extension: The early agreements. Journal of Agricultural Education, 37(1), 9-14.

Hirschi, T. (1969). The causes of delinquency. Berkley, CA: University of California Press.

Hoover, A., \& Weisenbach, A. (1999). Youth leading now! Securing a place at the table. New Designs for Youth Development, 15(3), 29-35. Retrieved on March 21, 2005 from: http://www.cydjournal.org/NewDesigns/ND 99Sum/Hoover.html 
Justinianno, J., \& Scherer, C. (2001). Youth voice: A guide for engaging youth in leadership and decision-making in service-learning programs. Washington, DC: Points of Light Foundation.

Knowles-Yánez, K. (2005). Children's participation in planning processes. Journal of Planning Literature, 20(1), 3-14.

Kothari, R. (1996, December). Youth participation in youth development. Paper presented at the Annual Meeting of the Comparative and International Education Society in Mexico City, Mexico.

Laidlaw Foundation. (2001). Youth as decision makers: Strategies for youth in governance and decision-making in recreation. Retrieved on March 26, 2005 from:

http://www.laidlawfdn.org/files/YADM-fullreport.pdf

Larson, R. (2000). Toward a psychology of positive youth development. American Psychologist, 55(1), 170-183.

Mason, H., \& Goll, R. (2000). Youth-adult review of research findings: Hampton Coalition for Youth (Appendix A). In Zeldin, S., McDaniel, A., Topitzes, D., \& Calvert, M. Youth indecisionmaking. Washington, DC: National 4-H Council. Retrieved March 5, 2005 from:

www.atthetable.com

Meucci, S., \& Redmon, J. (1997). Safe spaces: California children enter a policy debate. Social Justice, 24(3), 139-51.

Miles, M.B, \& Huberman, A.M. (1994). Qualitative data analysis, 2nd Ed., p. 10-12. Newbury Park, CA: Sage.

Ministry of Youth Affairs. (2002). Youth development strategy aoteatoroa: Action for child and youth development. Retrieved on August 29, 2006 from:

https://www.myd.govt.nz/uploads/docs/0.7.6.5\%20ydsa.pdf

National Youth Development Information Center (2000). What works: Essential elements of effective youth development programs. Retrieved on February 22, 2006 from:

http://www.nydic.org

Newsome, J., \& Scarela, J. (2001). Youth and boards: What's the status? San Francisco Youth Leadership Institute. Retrieved on May 4, 2005 from:

http://www.theinnovationcenter.org/pdfs/At the Table Catalog.pdf

Parker, L. (1999). If all youth served: Empowering youth to build community through service. Scottsdale, AZ: Corporation for National Service. Retrieved March 5, 2005 from: http://www.cns.gov

Pittman, K. (2000). Balancing the equation: Communities supporting youth, youth supporting communities. Community Youth Development Journal, 1, 33-36. 
Pittman, K., \& Wright, M. (1991). Bridging the gap: A rationale for enhancing the role of community organizations in promoting youth development. Washington, DC: Center for Youth Development and Policy Research.

Redd, Z., Brooks, J., \& McGarvey, A. (2002). Educating America's youth: What makes a difference. Retrieved on July 16, 2006 from:

http://www.childtrends.org/Files/K4Brief.pdf\#search=\%22Redd\%2C\%20Brooks $\% 20 \% 26 \% 20 \mathrm{M}$ cGarvey\%2C\%202002\%22

Scales, P., \& Leffert, N. (1999). Developmental assets: A synthesis of the scientific research on adolescent development. Minneapolis: Search Institute.

Young, K., \& Sazama, J. (1999). Fourteen points: Successfully engaging youth in decisionmaking. Somerville, MA: Youth on Board.

Zeldin, S., McDaniel, A., Topitzes, D., \& Calvert, M. (2000). Youth in decision-making: A study on the impacts of youth on adults and organizations. Chevy Chase, MD: Innovation Center for Community and Youth Development.

(C) Copyright of Journal of Youth Development Bridging Research and Practice. Content may not be copied or emailed to multiple sites or posted to a listserv without copyright holder's express written permission. Contact Editor at: patricia.dawson@oregonstate.edu for details. However, users may print, download or email articles for individual use.

ISSN 2325-4009 (Print); ISSN 2325-4017 (Online) 